
\title{
28 Research Square \\ Docked ions: vertical-aligned tubular arrays for highly efficient capacitive deionization
}

\section{Zhi-Yong Luo}

The Chinese University of Hong Kong, Shenzhen

\section{Dong Wang}

The Chinese University of Hong Kong, Shenzhen

\section{Lingqi Huang}

School of Science and Engineering, The Chinese University of Hong Kong,

\section{Xiangyang Liu}

The Chinese University of Hong Kong, Shenzhen

\section{Qi Zhang}

The Chinese University of Hong Kong, Shenzhen https://orcid.org/0000-0002-5770-4426

HeZhu ( $\nabla$ zhuhe@cuhk.edu.cn )

The Chinese University of Hong Kong, Shenzhen https://orcid.org/0000-0001-7731-6837

\section{Shiping Zhu}

The Chinese University of Hong Kong, Shenzhen

\section{Article}

Keywords: ion-docking effect, capacitive deionization, TiO2 nanotubes, vertically-aligned nanotubular structure

Posted Date: November 30th, 2021

DOI: https://doi.org/10.21203/rs.3.rs-1073985/v1

License: (c) (i) This work is licensed under a Creative Commons Attribution 4.0 International License. Read Full License 


\section{Abstract}

Capacitive deionization (CDI) is an effective method for desalination of brackish water to alleviate the global freshwater crisis. Obtaining high desalination capacity is the primary focus of this field. Based on electrical double layer (EDL) theory, current research is mainly devoted to increasing the specific surface area of electrode materials, however, the $\mathrm{NaCl}$ adsorption capacity is typically limited to the range of 10 $20 \mathrm{mg} \mathrm{g}^{-1}$. In this work, we propose a new design paradigm of using a vertical-aligned nanotubular structure for CDI. This design allows ions to be temporarily held inside the electrodes like ships docked in a harbor (ion-docking effect, IDE) due to the greatly diminished water flow inside the tubes, thus enhancing the desalination capacity. As a result, the obtained CDI device based on vertical-aligned nanotubular $\mathrm{P}-\mathrm{TiO}_{2}$ arrays shows an ultra-high $\mathrm{NaCl}$ adsorption capacity of $\sim 60 \mathrm{mg} \mathrm{g}^{-1}$ within 30 minutes in $0.01 \mathrm{~mol} \mathrm{~L}^{-1} \mathrm{NaCl}$ solution under $1.2 \mathrm{~V}$, corresponding to a rapid average adsorption rate of 2 $\mathrm{mg} \mathrm{g}^{-1} \mathrm{~min}^{-1}$. Moreover, the adsorption capacity could be further increased up to 121 and $136 \mathrm{mg} \mathrm{g}^{-1}$ under 1.2 and $1.5 \mathrm{~V}$ for 2.5 hours adsorption, respectively, but still far from its equilibrium value. Finally, experiments and theoretical simulations are combined to further understand the IDE in CDI. This work highlights the discovery and the utilization of IDE in CDI, and provides new guidance for the design of CDI electrodes and can facilitate the development of CDI technology.

\section{Introduction}

In recent years, the freshwater crisis has become a global issue owing to the growing population and the environmental pollution. ${ }^{1-2}$ Desalination is an effective method of acquiring freshwater from brackish water to alleviate this crisis. ${ }^{3-6}$ Current prevailing desalination technologies like distillation, reverse osmosis, and electrodialysis usually suffer from some drawbacks, including high energy consumption, secondary pollution, tedious operation, etc. Due to the low energy consumption and high efficiency, capacitive deionization (CDI) is proved to be a promising desalination technology based on the electrical double layer $(E D L)^{7-9}$ theory, and has drawn intensive attention. ${ }^{10-14}$

During the CDI process, a low voltage (e.g. 1.2 V) is applied to the electrodes producing positively and negatively charged poles. The cations (e.g. $\mathrm{Na}^{+}$) are attracted to the negative electrode while the anions (e.g. $\mathrm{Cl}^{-}$) are attracted to the positive electrode to form the EDL, respectively, thereby are removed from the brackish water. The overall CDI performance is determined by two consecutive steps, namely ion migration and ion adsorption. In the step of ion migration, salt ions migrate from the brackish water stream into the electrode materials driven by the electrostatic forces. In the next step of ion adsorption, salt ions are adsorbed on the electrode materials based on EDL and are held in place, allowing freshwater to flow out. The majority of the previous efforts has been devoted to enhancing the ion adsorption by increasing the capacitance, electrical conductivity, and most importantly, the specific surface areas of the electrode materials. ${ }^{15-18}$ For example, an excellent adsorption capacity of $45 \mathrm{mg} \mathrm{g}^{-1}$ was achieved using MXene aerogel electrodes in comparison with the restacked MXene electrodes with low specific surface 
area. Although a few encouraging results have been reported, the $\mathrm{NaCl}$ adsorption capacity is typically limited to the range of $10-20 \mathrm{mg} \mathrm{g}^{-1}, 15$ which is mainly due to limitation of the EDL mechanism.

This close examination of the CDI process has made us realize that ions do not necessarily have to form the EDL on the surface of the electrodes in order to be removed from the brackish water, as long as they are separated from the main water stream, the salt adsorption capacity can be improved. Bearing this in mind, we shift our focus to achieving the ion separation. Generally, when the ions migrate into but are not yet captured by the electrode materials, they remain free, and due to the prevailing rough surface and interconnected porous structure design paradigms of most current electrode materials, these ions can be easily brought back to the main stream by the flowing water (Scheme 1a). However, if these free ions are not disturbed by the water flow after entering into the electrode materials, they can be temporarily held inside the materials like ships docked in a harbor (ion-docking effect, IDE), and thus separated from the main water stream. Due to this additional contribution, the adsorption capacity can be greatly improved (in this work, we continue to use "adsorption" and "desorption" in order to be consistent with the commonly used terminologies, although some ions are not technically adsorbed to and desorbed from the surface). Therefore, we propose a vertical-aligned tubular array structure for the electrode materials to dock the ions inside the materials. Once the ions migrate into the tubular channel, they are separated from the main water flow. Since all tubes are long and not interconnected with each other, effect of water flushing is greatly diminished and the major force driving the ions back into the main water flow is the concentration gradient, which is compensated by the electrostatic force. As a result, the ions are held in place in the channel even if they are not confined in the EDL, making each tube acts like a concentrated brackish water reservoir, thus greatly enhancing the adsorption capacity (Scheme 1b).

Herein, we use a phosphated $\mathrm{TiO}_{2}\left(\mathrm{P}_{-} \mathrm{TiO}_{2}\right)$-based vertical-aligned nanotubular structure for $\mathrm{CDI}$ as the example to verify the IDE. The device displayed an ultra-high $\mathrm{NaCl}$ adsorption capacity of $\sim 60 \mathrm{mg} \mathrm{g}^{-1}$ within 30 minutes in $0.01 \mathrm{~mol} \mathrm{~L}^{-1} \mathrm{NaCl}$ solution under $1.2 \mathrm{~V}$, corresponding to a rapid average adsorption rate of $2 \mathrm{mg} \mathrm{g}^{-1} \mathrm{~min}^{-1}$. Moreover, the adsorption capacity could be further increased up to 121 and 136 $\mathrm{mg} \mathrm{g}^{-1}$ under 1.2 and $1.5 \mathrm{~V}$ for 2.5 hours adsorption, respectively, without reaching the equilibrium, indicating that the ions were not only confined in the EDL but also docked inside the nanotubes. These values are approximately one order of magnitude higher than those EDL-based CDI devices, therefore, this preliminary work of using vertical-aligned nanotubular structure for $\mathrm{CDI}$ opens up new avenues toward the structural design of electrodes based on IDE for highly efficient CDI and other related applications.

\section{Results And Discussion}

The vertical-aligned $\mathrm{P}-\mathrm{TiO}_{2}$ nanotubular arrays were fabricated by a two-step anodization method, followed by phosphorization (Figure 1a). ${ }^{19}$ The phosphorization process was necessary to enhance the electrochemical capacitance as well as the electrical conductivity (Figure S1a-c and Table S1). In addition, $\mathrm{P}-\mathrm{TiO}_{2}$ displayed remarkable cyclic stability, fulfilling the basic requirements for $\mathrm{CDI}$ electrodes (Figure S1d). The morphology was then studied by scanning electron microscopy (SEM). The top-view of 
$\mathrm{P}-\mathrm{TiO}_{2}$, as shown in Figure $1 \mathrm{~b}$ and Figure $1 \mathrm{c}$, revealed that the material displayed a highly ordered nanotubular structure with an average inner diameter of $\sim 100 \mathrm{~nm}$ and a wall thickness of $\sim 30 \mathrm{~nm}$. The cross-section view of $\mathrm{P}^{-} \mathrm{TiO}_{2}$ showed a thickness or nanotube length of $\sim 8 \mu \mathrm{m}$ (Figure 1d). As shown in Figure $1 \mathrm{e}$, the nanotubes were uniform in size along their length, and no interconnections could be observed between them. To further understand the atomic structure and composition of the $\mathrm{P}$ - $\mathrm{TiO}_{2}$, X-ray diffraction (XRD), X-ray photoelectron spectroscopy (XPS) and energy-dispersive X-ray spectroscopy (EDX) analyses were carried out. As shown in Figure $1 \mathrm{f}$, the as-prepared $\mathrm{TiO}_{2}$ before phosphorization showed the crystal phase of titanium substrate, indicating its amorphous structure, while the $\mathrm{P}-\mathrm{TiO}_{2}$ displayed the standard anatase phase (JCPDS-21-1272). This structural change was attributed solely to the high temperature used for phosphorization since the $\mathrm{TiO}_{2}\left(\mathrm{~A}-\mathrm{TiO}_{2}\right)$ prepared under the same condition as $\mathrm{P}-\mathrm{TiO}_{2}$ without addition of the phosphorization agent showed the same diffraction pattern. The existence of phosphorus in $\mathrm{P}_{-} \mathrm{TiO}_{2}$ was confirmed by the XPS (Figure S2) and EDX results (Figure S3). The $01 \mathrm{~s}$ spectrum shown in Figure $1 \mathrm{~g}$ clearly demonstrated the phosphorus groups ${ }^{19}$ were present in the form of Ti-O-P and O-P, which were located at 532.0 and $533.5 \mathrm{eV}$, respectively. The other surfaces oxygen species of the $\mathrm{P}_{-} \mathrm{TiO}_{2}$ located at $530.2,530.7$, and $531.2 \mathrm{eV}$ were attributed to lattice oxygen (Ti-0), ${ }^{20}$ defects, ${ }^{21}$ and surface hydroxyl groups $(\mathrm{Ti}-\mathrm{OH}),{ }^{22}$ respectively.

To prove our IDE concept, a prototype of CDI was designed as shown in Figure 2a. The device was assembled from a home-made CDI cell, a separator, a cation-exchange membrane, an anion-exchange membrane, and electrodes (i.e. vertical-aligned nanotubular $\mathrm{P}_{-} \mathrm{TiO}_{2}$ arrays) (Figure S4). The $\mathrm{NaCl}$ solution was cycled in the CDI system (Figure S5) and the $\mathrm{NaCl}$ concentration was in-situ analyzed via a conductivity meter. During the desalination process, the $\mathrm{NaCl}$ concentration regularly decreased from $\sim 590 \mathrm{mg} \mathrm{L}^{-1}$ to $\sim 550 \mathrm{mg} \mathrm{L}^{-1}$ within 30 minutes under $1.2 \mathrm{~V}$ (Figure $2 \mathrm{~b}$ ), corresponding to a salt adsorption capacity of approximately $60 \mathrm{mg} \mathrm{g}^{-1}$ and an average adsorption rate of $2 \mathrm{mg} \mathrm{g}^{-1} \mathrm{~min}^{-1}$. For comparison, $\mathrm{P}-\mathrm{TiO}_{2}$ powders and $\mathrm{P}-\mathrm{TiO}_{2}$ random nanotubes were synthesized to prepare $\mathrm{CDI}$ electrodes. Figure $\mathbf{S 6}$ showed the schematic structures of the three electrodes, and SEM images of the electrodes based on $\mathrm{P}-\mathrm{TiO}_{2}$ powders and $\mathrm{P}-\mathrm{TiO}_{2}$ random nanotubes were presented in Figure 2c, respectively. As shown in Figure $2 \mathrm{~d}, \mathrm{CDI}$ devices based on $\mathrm{P}-\mathrm{TiO}_{2}$ powders and $\mathrm{P}^{-\mathrm{TiO}_{2}}$ random nanotubes exhibited $\mathrm{NaCl}$ adsorption capacities of 11 and $18 \mathrm{mg} \mathrm{g}^{-1}$, respectively, corresponding to $18 \%$ and $30 \%$ of the device based on vertical-aligned nanotubular $\mathrm{P}-\mathrm{TiO}_{2}$ arrays. In the case of $\mathrm{P}-\mathrm{TiO}_{2}$ powders, the ions present in the interparticle pores were able to be flushed back to the main water stream due to the interconnected structure, therefore, the salt adsorption capacity was solely contributed by the ions held by the EDL. While in the case of $\mathrm{P}^{-\mathrm{TiO}_{2}}$ random nanotubes, due to the random orientation of the nanotube openings, it was difficult for the ions to enter the nanotubular channels, i.e., IDE was not significant, thus the salt adsorption capacity was slightly enhanced compared to $\mathrm{P}-\mathrm{TiO}_{2}$ powders but still much lower than vertical-aligned nanotubular $\mathrm{P}-\mathrm{TiO}_{2}$ arrays. These results indicated that the presence of IDE could dramatically enhance the performance of $\mathrm{CDI}$ devices. Moreover, the $\mathrm{NaCl}$ adsorption capacity of verticalaligned nanotubular $\mathrm{P}-\mathrm{TiO}_{2}$ arrays was still well below its equilibrium after 30 minutes, and reached up to 
$121 \mathrm{mg} \mathrm{g}^{-1}$ by prolonging the adsorption time to 2.5 hours. This value can be further improved to $136 \mathrm{mg}$ $\mathrm{g}^{-1}$ when the applied voltage was increased to $1.5 \mathrm{~V}$ (Figure 2e). These values were very remarkable, being approximately one order of magnitude higher than those EDL-based CDI devices, especially considering the low specific surface area of the tubular arrays (Figure S7). Figure $2 f$ showed the comparison of the $\mathrm{NaCl}$ adsorption capacity as a function of time for our work and the reported works, where the $\mathrm{GO} / \mathrm{TiO}_{2},{ }^{23} \mathrm{AC},{ }^{24} \mathrm{~N}$-porous carbon, ${ }^{25} \mathrm{~N}$-graphene, ${ }^{26}$ graphene $/ \mathrm{V}_{2} \mathrm{O}_{5},{ }^{27} \mathrm{MoS}_{2},{ }^{28} \mathrm{MXene}{ }^{29-30}$ and porous $\mathrm{Ti}_{3} \mathrm{C}_{2} \mathrm{~T}_{\mathrm{x}}{ }^{15}$ were taken into consideration. The $\mathrm{NaCl}$ adsorption capacity of a large proportion of materials falls into the range between 10 to $20 \mathrm{mg} \mathrm{g}^{-1}$ (the orange region in Figure $2 \mathrm{f}$ ). It is evident that the vertical-aligned nanotubular $\mathrm{P}-\mathrm{TiO}_{2}$ arrays outperformed in terms of both the salt adsorption capacity and salt adsorption rate, indicating that our CDI device is very promising in the desalination applications.

Next, in order to further understand IDE, the ion desorption behavior of the vertical-aligned nanotubular P$\mathrm{TiO}_{2}$ arrays was investigated. As shown in Figure $3 \mathrm{a}$, the ions removed from the brackish water could not be completely released within 30 minutes after the removal of electric field, and it was the same under different desalination times (Figure S8). This phenomenon was different from the desorption curves of previous reports ${ }^{15,23}$ and the $\mathrm{P}^{-\mathrm{TiO}_{2}}$ powder (blue line in Figure $3 \mathrm{a}$ ), in which the adsorbed ions were completely released in a short period of time. In the meantime, the flow velocity of the main water stream barely affected the desorption behavior of the vertical-aligned nanotubular $\mathrm{P}^{-\mathrm{TiO}_{2}}$ arrays (Figure $3 \mathrm{~b}$ ), while in the case of $\mathrm{P}-\mathrm{TiO}_{2}$ powder, the ion desorption rate slowed down clearly with the decrease of the flow velocity, as shown in Figure 3c. These results once again proved our concept of IDE. Due to the current design paradigm of rough surface and interconnected porous electrode materials, the adsorbed ions could be flushed away easily once the electric field disappeared, thus presenting a complete, rapid, and water-flow-velocity-dependent desorption behavior. However, in the case of vertical-aligned nanotubular $\mathrm{P}-\mathrm{TiO}_{2}$ arrays, the ions inside the nanotubular channels were relatively independent of the influence of the water flow, i.e., the IDE was significant, only the concentration gradient would act as the driving force forcing the ions to diffuse back into the main water stream, leading to a slow ion desorption behavior. However, by applying a reverse voltage of $-1.2 \mathrm{~V}$, the ions could be completed desorbed within 30 minutes due to the presence of additional electrostatic repulsion (black line in Figure 3a). Thanks to this good reversibility, the device based on vertical-aligned nanotubular $\mathrm{P}^{-\mathrm{TiO}_{2}}$ arrays delivered an excellent cyclic stability (Figure 3d), demonstrating its great potential in practical applications.

Finally, a mathematical model was proposed to simulate the ion desorption behaviors of the devices based on powders and vertical-aligned nanotubular arrays under $0 \mathrm{~V}$. It should be noted that the electrode based on powders was approximated as a rough surface composed of triangles (Figure S9), and such approximation should be applied to most electrodes stacked by functional materials including nanoparticles, nanosheets, and nanowires. In order to model the process of ion desorption from the nanotubular structure, we mainly considered the effect of the transportation of fluid flow and the effect from the unequal distribution of ions in space (more detailed information can be found in the Supporting Information). We firstly simulated the flow fields of both cases. Figure 4a showed the distribution of 
visual flow field of rough surface, which revealed the water flushing effect in the cavities of rough surface (Scheme 1a), thus the ions could be easily brought back to the main stream by the flowing water during the ion desorption process. However, for the case of tubular arrays, only the surficial water inside the tubes was affected by the main stream, while the main part of the water body below remained stationary (Figure $4 b$ ), thus making it possible to temporarily dock the ions inside the tubes, i.e. IDE. Subsequently, the ion desorption behaviors in both cases were calculated. As shown in Figure 4c, the rough surface showed a much faster ion desorption rate and a stronger dependence on the flow velocity of the main stream compared to tubular arrays. These simulation results were in good accordance with the experiment data (Figure 3b-c), confirming the existence and importance of IDE in the vertical-aligned nanotubular $\mathrm{P}-\mathrm{TiO}_{2}$ arrays designed above. In addition, to promote the practical application of IDE in CDI, the effects of diameter and length of tubular structure on IDE were studied via simulation, and the results indicated that IDE could be enhanced by increasing the length (Figure 4d) and decreasing the diameter of the tubes (Figure 4e). The simulation results provide clear insights into the structural design of electrodes for efficient IDE-based CDI devices.

In summary, we demonstrated a new design paradigm for CDI by using a vertical-aligned nanotubular structure, which displayed an ultra-high $\mathrm{NaCl}$ adsorption capacity of $\sim 60 \mathrm{mg} \mathrm{g}^{-1}$ within 30 minutes in 0.01 mol L-1 $\mathrm{NaCl}$ solution under $1.2 \mathrm{~V}$, corresponding to a rapid average adsorption rate of $2 \mathrm{mg} \mathrm{g}^{-1} \mathrm{~min}^{-1}$. Moreover, the $\mathrm{NaCl}$ adsorption capacity reached up to 121 and $136 \mathrm{mg} \mathrm{g}^{-1}$ under 1.2 and $1.5 \mathrm{~V}$, respectively, by prolonging the adsorption time to 2.5 hours. The remarkable CDI performance of verticalaligned nanotubular structure was attributed to the additional contribution from IDE besides EDL, and was illustrated by the combination of experiments and theoretical simulations. We believe this work opens up new avenues toward the structural design of electrodes for highly efficient CDI and other electrochemical applications.

\section{Methods}

Experimental methods and any associated references can be found in the Supporting Information.

\section{Declarations}

\section{Acknowledgements}

Z. Y. L. and D. W. contributed equally to this work. This work was financially supported by Shenzhen Science and Technology Program (Grant KQTD20170810141424366), 2019 Special Program for Central Government Guiding Local Science and Technology Development: Environmental Purification Functional Materials Research Platform, National Natural Science Foundation of China (Grant 22005260 \& 22078276), Program for Guangdong Introducing Innovative and Entrepreneurial Teams (Grant 2017ZT07C291), Shenzhen Key Laboratory of Advanced Materials Product Engineering (Grant ZDSYS20190911164401990), and China Postdoctoral Science Foundation (Grant 2020M671866). Dong acknowledges the support from National Natural Science Foundation of China (Grant 12101524) and the 
University Development Fund from The Chinese University of Hong Kong, Shenzhen (Grant UDF01001803).

\section{Author Contributions}

Z.-Y. L., H. Z. and S. Z. proposed the IDE concept and designed the experiments. Z.-Y. L. L. H. and X. L. carried out the experiments. D. W. built the mathematical model. All authors analysed data. All authors interpreted data and wrote the paper.

Supplementary Information accompanies this paper at https://doi.org/xxxxxx.

Competing interests: The authors declare no conflict of interest.

\section{References}

1. Elimelech, M., Phillip, W. A. The future of seawater desalination: energy, technology, and the environment. Science 333, 712-717 (2011).

2. Sheikholeslami, R. Strategies for future research and development in desalination - challenges ahead. Desalination 248, 218-224 (2009).

3. Suss, M. E., Presser, V. Water desalination with energy storage electrode materials. Joule 2, 10-15 (2018).

4. Subramani, A., Jacangelo, J. G. Emerging desalination technologies for water treatment: a critical review. Water Res. 75, 164-187 (2015).

5. AlMarzooqi, F. A., Al Ghaferi, A. A., Saadat, I., Hilal, N. Application of capacitive deionisation in water desalination: a review. Desalination 342, 3-15 (2014).

6. Porada, S., Zhao, R., van der Wal, A., Presser, V., Biesheuvel, P. M. Review on the science and technology of water desalination by capacitive deionization. Prog. Mater. Sci. 58, 1388-1442 (2013).

7. Nie, J., Ren, Z., Xu, L., Lin, S., Zhan, F., Chen, X., Wang, Z. L. Probing contact-electrification-induced electron and ion transfers at a liquid-solid interface. Adv. Mater. e1905696 (2019).

8. Grun, F., Jardat, M., Turq, P., Amatore, C. Relaxation of the electrical double layer after an electron transfer approached by brownian dynamics simulation. J. Chem. Phys. 120, 9648-9655 (2004).

9. Boyd, S., Ganeshan, K., Tsai, W. Y., Wu, T., Saeed, S., Jiang, D. E., Balke, N., Van Duin, A. C. T., Augustyn, V. Effects of interlayer confinement and hydration on capacitive charge storage in birnessite. Nat. Mater. https://doi.org/10.1038/s41563-021-01066-4 (2021).

10. Wang, L., Dykstra, J. E., Lin, S. Energy efficiency of capacitive deionization. Environ. Sci. Technol. 53, 3366-3378 (2019).

11. Chen, F., Huang, Y., Guo, L., Sun, L., Wang, Y., Yang, H. Y. Dual-ions electrochemical deionization: a desalination generator. Energ. Environ. Sci. 10, 2081-2089 (2017).

12. Hatzell, K. B., Boota, M., Gogotsi, Y. Materials for suspension (semi-solid) electrodes for energy and water technologies. Chem. Soc. Rev. 44, 8664-8687 (2015). 
13. Gamaethiralalage, J. G., Singh, K., Sahin, S., Yoon, J., Elimelech, M., Suss, M. E., Liang, P., Biesheuvel, P. M., Zornitta, R. L., de Smet, L. C. P. M. Recent advances in ion selectivity with capacitive deionization. Energ. Environ. Sci. 14, 1095-1120 (2021).

14. Yang, Z.-Y., Jin, L.-J., Lu, G.-Q., Xiao, Q.-Q., Zhang, Y.-X., Jing, L., Zhang, X.-X., Yan, Y.-M., Sun, K.-N. Sponge-templated preparation of high surface area graphene with ultrahigh capacitive deionization performance. Adv. Funct. Mater. 24, 3917-3925 (2014).

15. Bao, W., Tang, X., Guo, X., Choi, S., Wang, C., Gogotsi, Y., Wang, G. Porous cryo-dried mxene for efficient capacitive deionization. Joule 2, 778-787 (2018).

16. Santos, C., Rodríguez, I. V., Lado, J. J., Vila, M., García-Quismondo, E., Anderson, M. A., Palma, J., Vilatela, J. J. Low-energy consumption, free-form capacitive deionization through nanostructured networks. Carbon 176, 390-399 (2021).

17. Liu, T., Serrano, J., Elliott, J., Yang, X., Cathcart, W., Wang, Z., He, Z., Liu, G. Exceptional capacitive deionization rate and capacity by block copolymer-based porous carbon fibers. Sci. Adv. 6, eaaz0906 (2020).

18. Shi, W., Liu, X., Deng, T., Huang, S., Ding, M., Miao, X., Zhu, C., Zhu, Y., Liu, W., Wu, F., Gao, C., Yang, S. W., Yang, H. Y., Shen, J., Cao, X. Enabling superior sodium capture for efficient water desalination by a tubular polyaniline decorated with prussian blue nanocrystals. Adv. Mater. 32, e1907404 (2020).

19. Ni, J., Fu, S., Yuan, Y., Ma, L., Jiang, Y., Li, L., Lu, J. Boosting sodium storage in $\mathrm{TiO}_{2}$ nanotube arrays through surface phosphorylation. Adv. Mater. 30, 1704337 (2018).

20. Wang, D., Liu, Y., Liu, X., Zhou, F., Liu, W., Xue, Q. Towards a tunable and switchable water adhesion on $\mathrm{TiO}_{2}$ nanotube film with patterned wettability. Chem. Commun. 7018 (2009).

21. Luo, Z.-Y., Lyu, S.-S., Wang, Y.-Q., Mo, D.-C. Fluorine-induced superhydrophilic Ti foam with surface nanocavities for effective oil-in-water emulsion separation. Ind. Eng. Chem. Res. 56, 699-707 (2017).

22. Lu, X., Wang, G., Zhai, T., Yu, M., Gan, J., Tong, Y., Li, Y. Hydrogenated $\mathrm{TiO}_{2}$ nanotube arrays for supercapacitors. Nano Lett. 12, 1690-1696 (2012).

23. Yin, H., Zhao, S., Wan, J., Tang, H., Chang, L., He, L., Zhao, H., Gao, Y., Tang, Z. Three-dimensional graphene/metal oxide nanoparticle hybrids for high-performance capacitive deionization of saline water. Adv. Mater. 25, 6270-6276 (2013).

24. Porada, S., Borchardt, L., Oschatz, M., Bryjak, M., Atchison, J. S., Keesman, K. J., Kaskel, S., Biesheuvel, P. M., Presser, V. Direct prediction of the desalination performance of porous carbon electrodes for capacitive deionization. Energ. Environ. Sci. 6, 3700 (2013).

25. Zhao, C., Liu, G., Sun, N., Zhang, X., Wang, G., Zhang, Y., Zhang, H., Zhao, H. Biomass-derived n-doped porous carbon as electrode materials for zn-air battery powered capacitive deionization. Chem. Eng. J. 334, 1270-1280 (2018).

26. Xu, X., Sun, Z., Chua, D. H., Pan, L. Novel nitrogen doped graphene sponge with ultrahigh capacitive deionization performance. Scientific Reports 5, 11225 (2015). 
27. Baburaj, A., Puthirath, A. B., Jain, A., Palanisamy, D., Salpekar, D., Balachandran, J., Kabbani, M. A., Hernandez, F. C. R., Hughes, G., Babu, G., Ajayan, P. M. Multilayer graphene coated vanadium(V) oxide as electrodes for intercalation based brackish water desalination. 2D Materials 7, 045025 (2020).

28. Xing, F., Li, T., Li, J., Zhu, H., Wang, N., Cao, X. Chemically exfoliated $\mathrm{MoS}_{2}$ for capacitive deionization of saline water. Nano Energy 31, 590-595 (2017).

29. Buczek, S., Barsoum, M. L., Uzun, S., Kurra, N., Andris, R., Pomerantseva, E., Mahmoud, K. A., Gogotsi, Y. Rational Design of Titanium Carbide Mxene Electrode Architectures for Hybrid Capacitive Deionization. Energ. Environ. Mater. 3, 398-404 (2020).

30. Srimuk, P., Kaasik, F., Krüner, B., Tolosa, A., Fleischmann, S., Jäckel, N., Tekeli, M. C., Aslan, M., Suss, M. E., Presser, V. Mxene as a novel intercalation-type pseudocapacitive cathode and anode for capacitive deionization. J. Mater. Chem. A 4, 18265-18271 (2016).

\section{Scheme}

Scheme 1 is available in the Supplemental Files section.

\section{Figures}


a
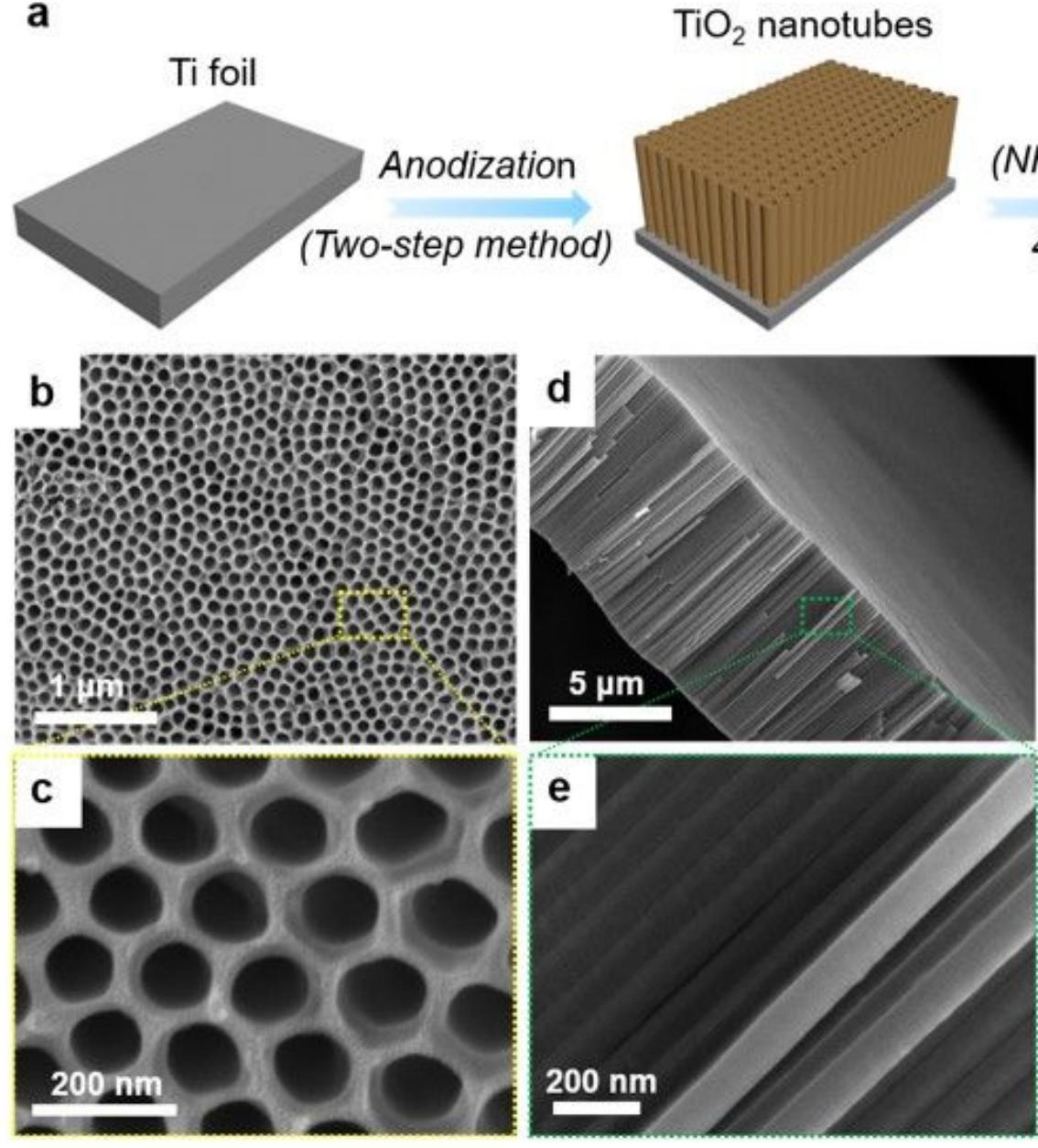
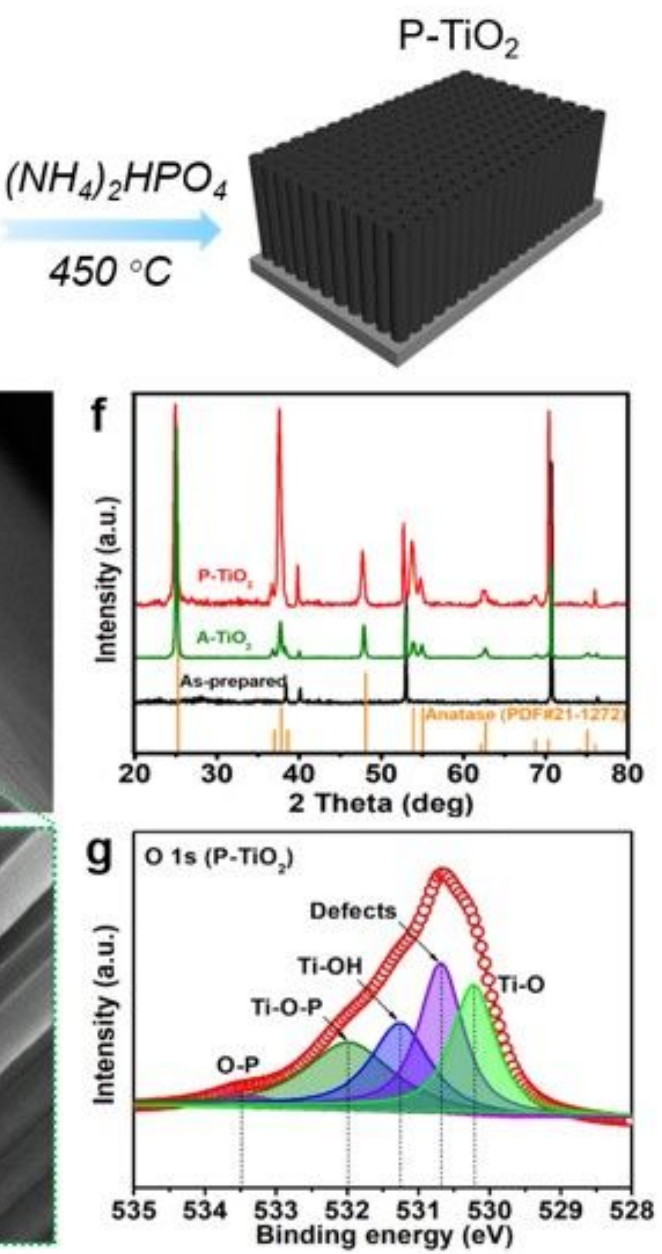

\section{Figure 1}

The materials preparation and characterization. (a) Preparation of P-TiO2-based vertical-aligned nanotubular structure. (b)-(c) SEM images of top-view of P-TiO2. (d)-(e) SEM images of cross-section view of P-TiO2. (f) XRD patterns of as-prepared TiO2, anatase TiO2 (A-TiO2) and P-TiO2, respectively. (g) XPS spectrum of 01 s of P-TiO2. 
a

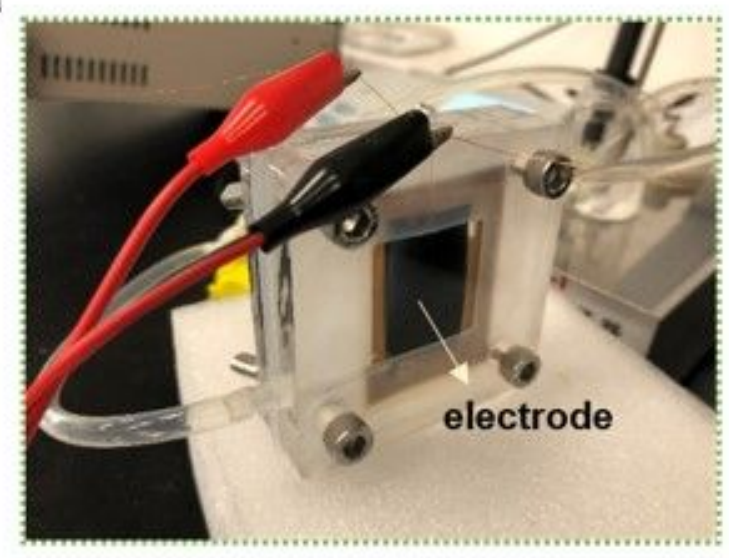

C

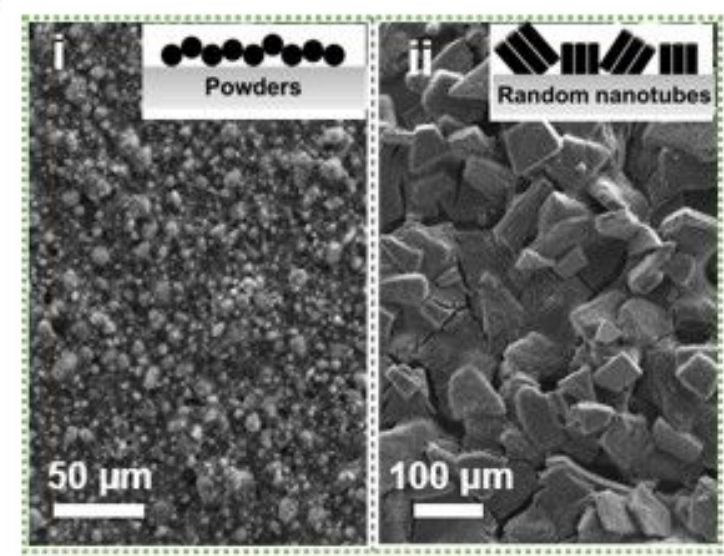

e

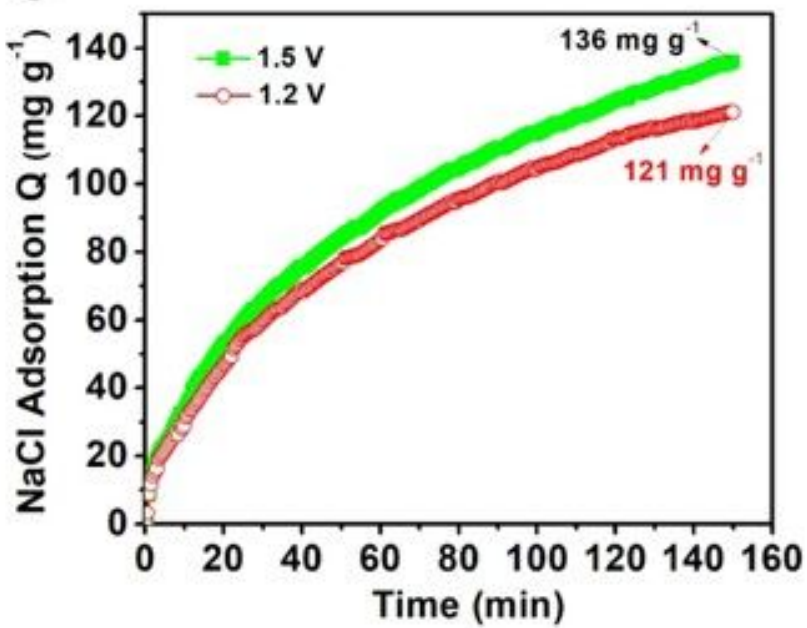

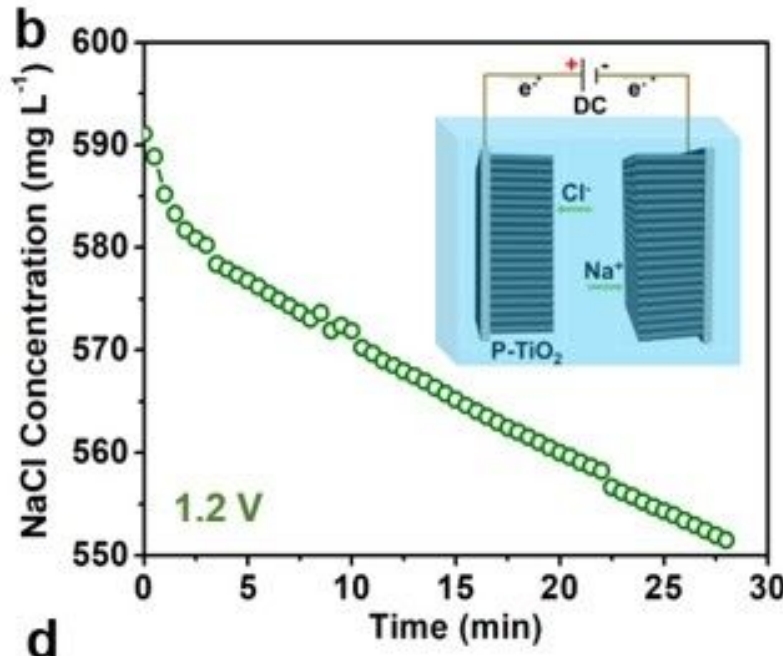

d
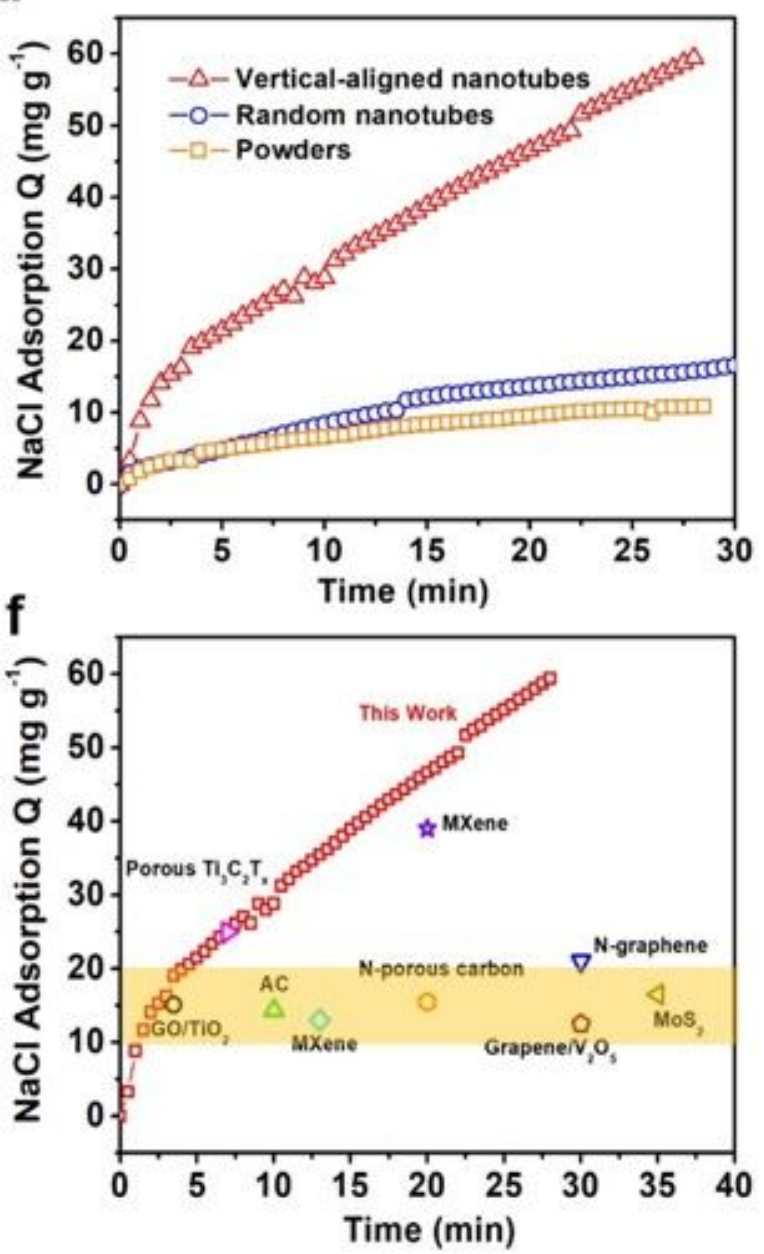

\section{Figure 2}

The adsorption process of CDI experiments. (a) The CDI prototype integrated with electrodes. (b) The ion adsorption curve of $\mathrm{CDI}$ device based on vertical-aligned nanotubes, inset presents the schematic illustration of CDI device. (c) SEM images of electrodes based on P-TiO2 powders and random P-TiO2 nanotubes. (d) The time-dependent $\mathrm{NaCl}$ adsorption capacity of the $\mathrm{CDI}$ device based on P-TiO2 powders, random nanotubes and vertical-aligned nanotubes, respectively. (e) The long-time ion adsorption curves 
of the vertical-aligned nanotubular P-TiO2 arrays under 1.2 V and 1.5 V, respectively. (f) The comparison of $\mathrm{NaCl}$ adsorption capacity of this work with reported literatures, where the applied voltage is $\sim 1.2 \mathrm{~V}$ and the initial $\mathrm{NaCl}$ concentration is $\sim 500 \mathrm{mg} \mathrm{L}-1$.
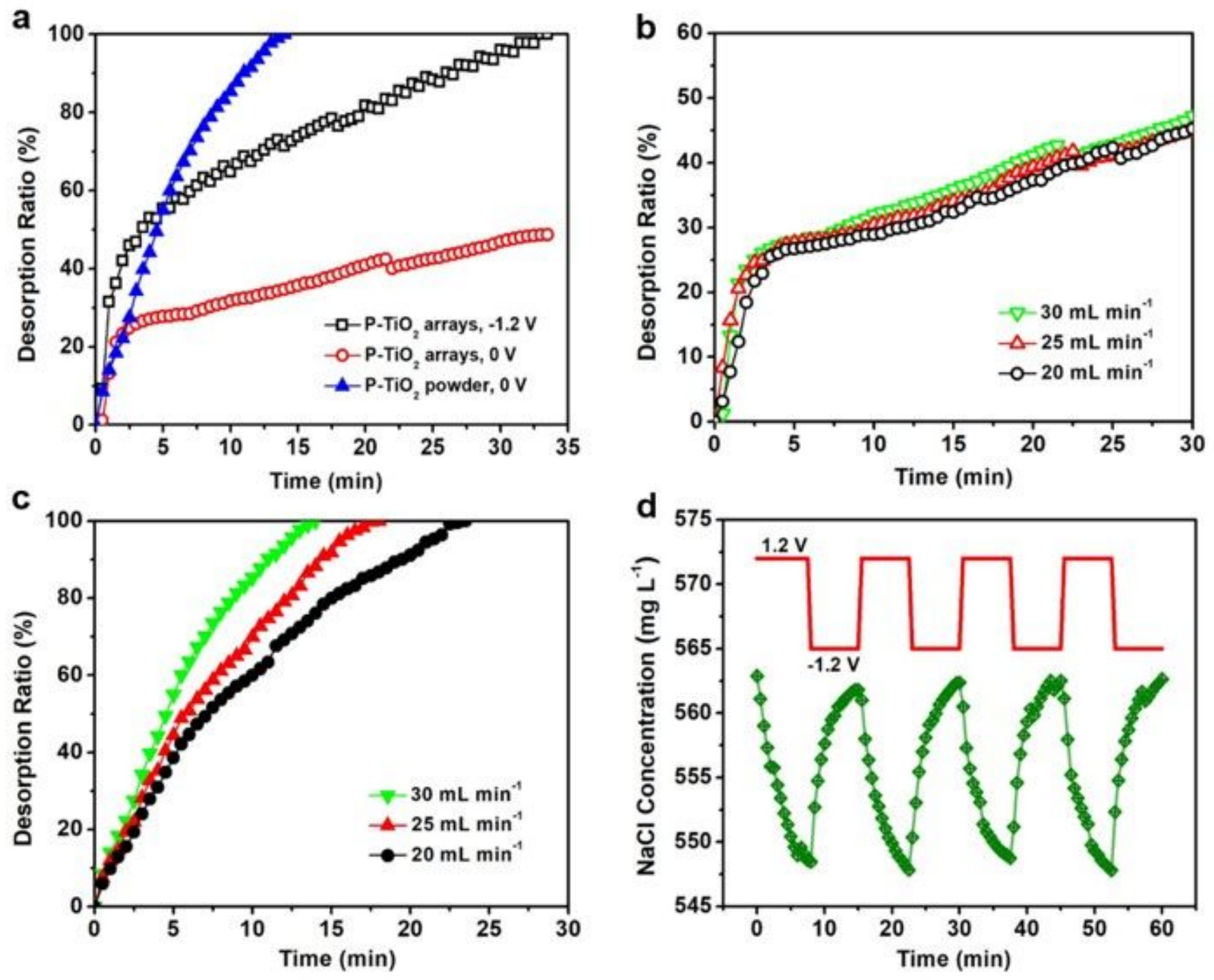

\section{Figure 3}

The desorption process of CDI experiments. (a) The ion desorption curves of CDI devices based on PTiO2 powder under $0 \mathrm{~V}$, and vertical-aligned nanotubular $\mathrm{P}-\mathrm{TiO} 2$ arrays under $-1.2 \mathrm{~V}$ and $0 \mathrm{~V}$, respectively. The effect of water flow velocity on the desorption behavior of CDI device based on (b) vertical-aligned nanotubular P-TiO2 arrays and (c) P-TiO2 powder. (d) The recyclability of the CDI device based on vertical-aligned nanotubular $\mathrm{P}-\mathrm{TiO} 2$ arrays. 
a

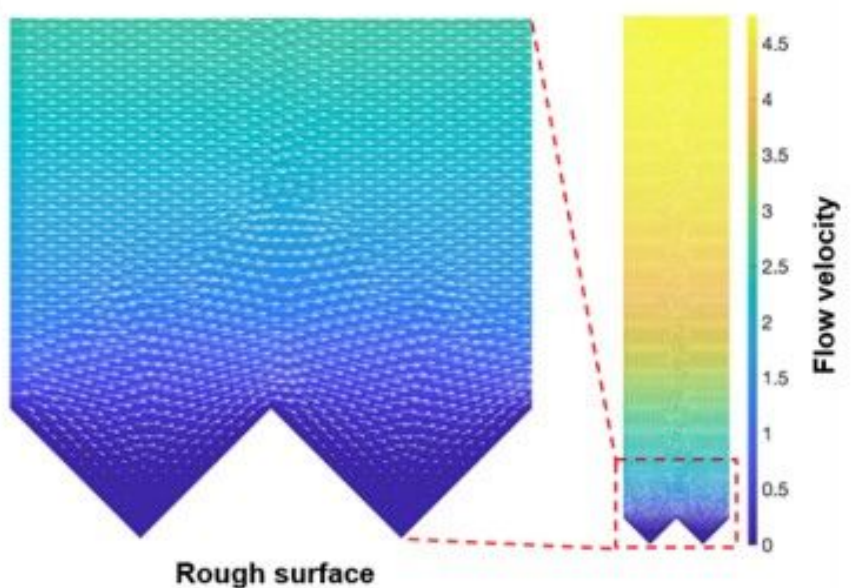

Rough surface

C

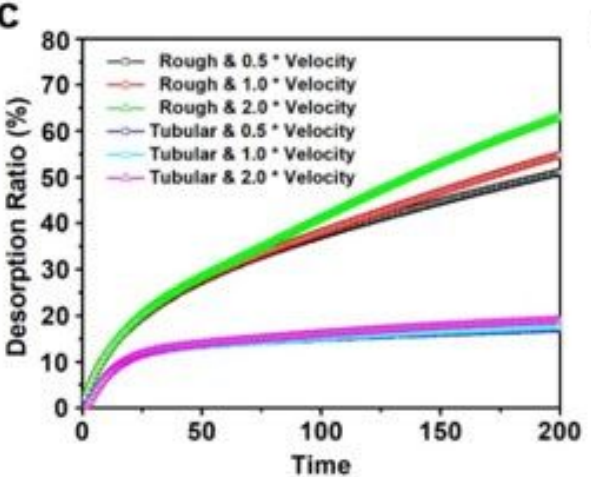

b

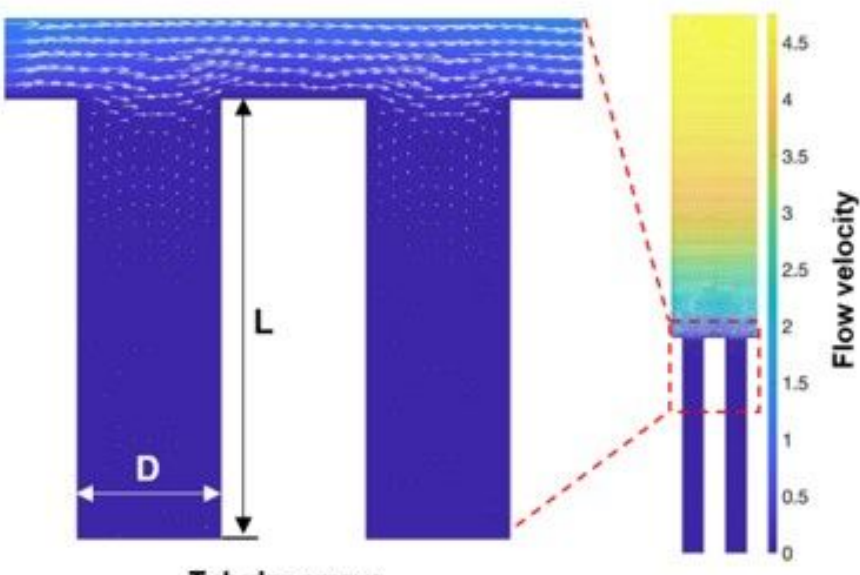

Tubular arrays

e

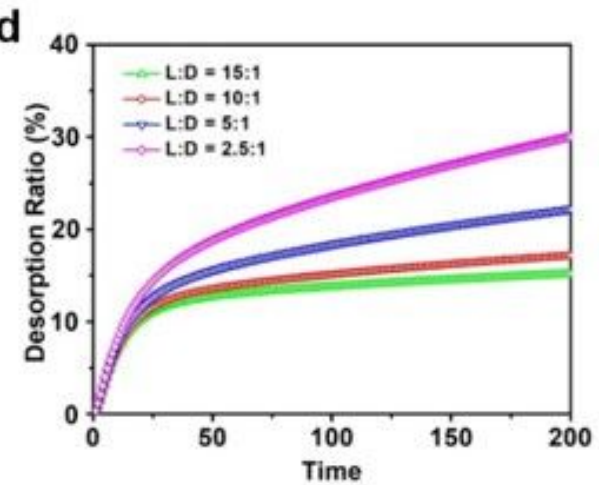

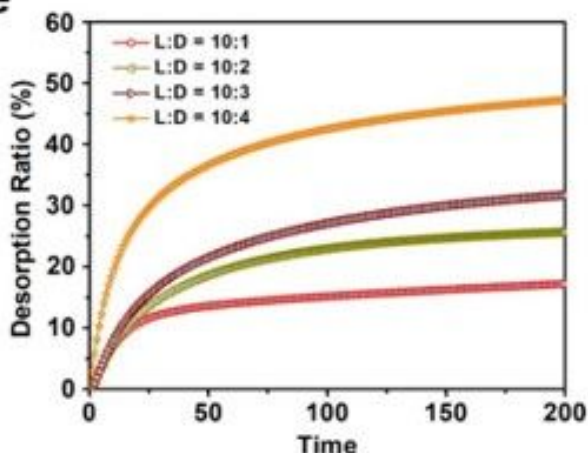

Figure 4

The mathematical simulation of ion desorption behavior. The distribution of visual flow field for (a) rough surface and (b) tubular arrays. (c) The spontaneous ion desorption curves of rough surface and tubular arrays under varied flow velocity. (d) The effect of tube length on IDE. (e) The effect of tube diameter on IDE.

\section{Supplementary Files}

This is a list of supplementary files associated with this preprint. Click to download.

- GraphicalAbstract.jpg

- Scheme1.jpg

- SupportingInformation.docx 